\title{
Role of Artificial Intelligence in Enhancing Efficiency of Accounting Information System and Non-Financial Performance of the Manufacturing Companies
}

\author{
Firas Hashem ${ }^{1}$, \& Rateb Alqatamin ${ }^{1}$ \\ ${ }^{1}$ College of Business, Tafila Technical University, Tafila, Jordan \\ Correspondence: Firas Hashem, College of Business, Tafila Technical University, Tafila, Jordan.
}

Received: October 13, 2021

Accepted: October 27, 2021

Online Published: November 5, 2021

doi:10.5539/ibr.v14n12p65

URL: https://doi.org/10.5539/ibr.v14n12p65

\begin{abstract}
The current study launched from the main objective of examining the impact of artificial intelligence (AI) and its role in supporting and improving the efficiency of AIS on one hand, and non-financial performance standards on the other. In order to achieve this goal and indicate the extent of its conformity with reality; quantitative approach was used and a questionnaire were adopted as a study tool, the questionnaire was distributed electronically to a sample of (409) managers, heads of departments and accountants in industrial establishments operating in Jordan during the fiscal year 2020/2021. By analyzing the primary data based on SPSS, the study came to the conclusion that AI techniques played a significant role in enhancing efficiency of AIS outcomes through focusing on outcomes' understandability, reliability, credibility and comparability, on another level, AI techniques also proved its ability to influence non-financial performance through focusing on feeding organization with the needed information that locates weak points and develop them, and strength points to exploit them. Study recommended the need to link the operations of intelligent systems to the goals of the organization as a whole and ensure the complete interdependence between the AIS systems and the accounting information in the systems.
\end{abstract}

Keywords: artificial intelligence, accounting information systems, expert systems, financial data, performance management, non-financial performance

\section{Introduction}

Organizations usually aim to reach a market share higher than their counterparts, and accordingly adopt all the tools and strategies to bring them to that level of performance that will maximize their market share, control it and push it forward (Vincent and Zakkariya, 2021). As a means, organizations implement many strategies, including developing their technological systems, trying to use machines more than people, controlling their financial deposits, evaluating employee performance and trying to maximize profitability over production costs (Astuti and Rahayu, 2018).

The financial and accounting aspect of the organization is one of the most important aspects that reflect the extent of its performance and effectiveness, and systems usually adopt all the tools and resources that guarantee access to strong accounting and financial outputs capable of clarifying the organization's position and the degree of its control over the market (Albuhisi and Abdallah, 2018). Now, technological tools and software are considered One of the most important elements that can maximize performance, and this technology was represented by artificial intelligence, which was able to provide the organization with many modern tools and software capable of replacing the human being and ensuring that the organization reaches a stage of excellence in performance on the financial and non-financial levels (Mjongwana and Kamala, 2018).

The current study stems from the relationship between the introduction of artificial intelligence systems in all its forms in organizational work, and how it can affect the performance of the organization in terms of its financial output, such as the adoption of accounting and financial information systems, in addition to the impact on non-financial performance such as employee performance, satisfaction Customer loyalty, inventory, quality and much more. 


\section{Problem Formulation}

Accounting is one of the fields like other fields that have been invaded by information technology and changed many of its features such as artificial intelligence, data analysis and block chain (Shrestha et al, 2019; Raisch and Krakowski, 2021). And there are many scholars and researchers who have predicted that automating accounting activities will eventually lead to the gradual disappearance of accountants and auditors, as this automation will facilitate the work of individuals who do not have sufficient experience in the field and thus dispense with the human element in accounting (Askary et al, 2018; Hamadneh et al, 2021).

It was argued by Al-Sayyed et al (2021) that artificial intelligence in accounting is considered an opportunity rather than a threat, as it helps accountants to stay abreast of the latest technology in the accounting field and prepares universities to graduate qualified accountants who link between accounting expertise and technological knowledge.

In general, the use of artificial intelligence in organizational productive, administrative and accounting processes is very important, and this importance comes from the entry of technology into many different processes in business environments, which led to the development and improvement of organizational work from all sides.

Accordingly, the current study seeks to determine the role of artificial intelligence in improving the efficiency of accounting information systems and maximizing the non-financial performance outputs in industrial organizations operating in Jordan for the fiscal year 2020-2021.

\section{Literature Review}

\section{Artificial Intelligence}

Artificial intelligence took off in the fifties of the twentieth century, when the scientist "Alan Turing" made what is called today the Turing Test in order to evaluate and classify the intelligence of computers (Holzinger et al, 2019; Acemoglu and Restrepo, 2019). After that, scientists from all over the world began designing software and smart devices that simulate human activities such as thinking, learning and shopping, and the first successful experiment in this field was by the scientist "Anthony Oettinger", who designed an experiment that simulates the shopping process carried out by the average person, which It led to the emergence of what is known today as Machine Learning, however, approached to artificial intelligence which were reached by scientists had different aspects leading to the design of devices that carry out exploration trips to dangerous and remote areas and return with pictures and information that benefit science and scientists (Vaishya et al, 2020).

As for $\mathrm{He}$ et al (2019) viewed artificial intelligence as one of the scientific efforts in facilitating human life by teaching machines to simulate human mental abilities and the way they work, thus mastering human skills through the machine and giving the human mind the opportunity to think and be creative in other matters, including problem solving and Develop various plans and strategies.

Artificial intelligence stems from computer science and is one of the most important current technological developments that have contributed significantly to changing the world and giving a great qualitative leap to the life that humans live today (Gunning and Aha, 2019). According to Haenlein and Kaplan (2019), Artificial intelligence is defined as the ability of computers and digital devices to complete tasks and things at a level that simulates humans, such as thinking, learning, solving problems, and dealing with other mental processes.

\section{Artificial Intelligence in Accounting}

Artificial intelligence appears in the accounting field in the form of computerized documents, audits and tax processes, in addition to many methods of fraud prevention (Kokina and Davenport, 2017). Accounting artificial intelligence has gained a lot of attention due to its ability to give accountants an opportunity to provide added value to accounting operations (Chukwudi et al, 2018).The importance of accounting artificial intelligence lies in its ability to give decision makers the space to carry out decision-making processes in an easy and smooth way by focusing on their duties and leaving the opportunity for artificial intelligence to do automated things, in other words, instead of individuals wasting their time in data entry, analysis and organization And to update them, this matter is left to smart systems while individuals focus on duties that require a human touch such as interpreting and analyzing outputs, matching them with reality and making decisions based on them, i.e. making accountants more efficient and productive (Ionescu, 2019).

From the point of view of Damerji and Salimi (2021), the role of artificial intelligence represented in giving accountants the opportunity to access the basics of different systems in addition to dealing with complex numbers and reducing the burden of accounting work by reducing the repetition of tasks and thus making smart financial decisions. As for Luo et al (2018) pointed out that artificial intelligence in accounting work would 
perform large-scale tasks that may be impossible for humans to complete, and the outputs of these tasks are highly accurate without errors provided that the inputs are basically correct and accurate. Faccia et al (2019) pointed out that artificial intelligence greatly helps in enhancing the audit process by detecting errors and removing incorrect requests, and the audit is real at the same time and based on the organization's policies and objectives.

\section{Accounting Information Systems}

Sari et al (2019) defined accounting information systems as a set of interrelated elements, tools, procedures, devices and software that would interact together to solve financial data analysis, control and supply when needed. Tjahjadi and Soewarno (2019) believe that accounting information systems consist of a set of elements, which are:

\section{- Human Resources}

It is the intellectual capital (employees) who have the expertise necessary to complete the accounting work and understand it and the ability to read and analyze it in a way that serves the decision-making process in the organization

\section{- Material resources}

It refers to the computer hardware, systems, software and physical tools that are used during the process of analyzing accounting data such as storage media, computer clouds, databases and related outputs and inputs.

\section{- $\quad$ - Financial data}

It is the primary and most important part, and it refers to the financial data that is entered into the systems for analysis, classification, processing, and then presenting it as information that serves decision-makers.

The importance of AIS lies in its ability to - primarily - regulate accounting work for organizations regardless of their size (Elsharif, 2019). In other meaning, AIS play an important role in managing financial performance of organization no matter what its size was, and it helps in defining the current and future situation of the organization from a financial perspective (Al-Hashimy et al, 2019). This helps in the process of decision making as it aid decision makers in making decisions that are related to the outcomes of AIS, this way, all risks measures can be taken into consideration which facilitates the process of reaching organizational excellence (Hariyati et al, 2019).

\section{Performance Management}

DeNisi and Murphy (2017) indicates that performance management is the method adopted by the organization in order to manage and control the performance of employees by relying on accurate data and information coupled with support and positive encouragement in order to raise the level of performance and thus help the organization reach a state of organizational excellence. Schleicher et al (2018) believes that performance management is a matter that depends on the interaction and cooperation of all the organization's elements, including departments, leaders, and individuals in order to reach specific goals that measure performance based on making accurate and up-to-date data and information available to everyone. On the other hand, Helmold and Samara (2019) pointed out that performance management aims to supervise and control employees and working individuals in order to ensure the efficient and effective running of organizational work, in addition to developing the tools and standards required to solve performance improvement.

In general, performance management aims to achieve a set of results, the most important of which is aligning the performance of employees with the goals and objectives of the organization, in addition to developing their performance outcomes to reach the stage of excellence (Richards et al, 2019). While Pulakos et al (2019) stressed that performance management is able to create measurable variables and thus be able to evaluate performance, on the other hand, performance management is one of the things that will determine the career path and indicate strengths and weaknesses in the performance of employees so that the Focus on developing their weaknesses and exploiting their strengths.

\section{Non-financial Performance}

Organizations usually aspire to reach a competitive advantage in order to increase their market share, here organizations focus on control systems in all its forms in order to identify and improve weaknesses, strengths and exploit them (Nguyen et al, 2020). Among the things that organizations focus on achieving is controlling non-financial performance and linking it to the organization's strategic goals such as quality, reliability, delivery time and many others (Albuhisi and Abdallah, 2018). 
Accordingly, non-financial performance measures refer to the organization's performance in other usually non-financial matters such as inventory, customer satisfaction, competitive advantage, delivery time of service or product, quality and many others (Nyarku and Ayekple, 2019). And Borodin et al (2019) sees that the non-financial indicators of performance are important matters that are comparable to the importance of financial indicators, as the profits of the digital organization and its investment income may not be an indication of its general performance, but the customer satisfaction and loyalty in addition to the time of delivery of the product or service and quality on standards that may They are important in reaching indicators that evaluate the performance of the organization in general.

\section{Hypotheses Development}

\section{Artificial intelligence positively influences efficiency of accounting information systems}

In a review of previous literature by Askary et al (2018) on the role of artificial intelligence in increasing the reliability of accounting output, the researchers came to the conclusion that artificial intelligence has not proven its ability to avoid the risks associated with accounting systems, justifying this with the idea that, in the end, no matter how accurate the systems are, the inputs are Who controls the outputs, and if the inputs are inaccurate, it is natural that the outputs are unreliable and weak. On another level, the study proved that the accounting artificial intelligence contributed significantly to reducing the percentage of losses associated with producing false and inaccurate accounting information, which helps senior management to take better accounting and financial decisions due to the quality and efficiency of the outputs of the accounting systems.

Study by Hamadneh et al (2021) aimed to determine the impact of artificial intelligence on the consistency, reliability and accuracy of financial data analysis. And by adopting the experimental exploratory approach, data were collected from (172) accountants and financial employees in all hotels located in the Aqaba Special Economic Zone. And by analyzing the data of the study based on SPSS, the study came to the conclusion that artificial intelligence in the accounting systems used in the hotels under study contributed significantly to increasing the reliability and consistency of the accounting output of these hotels, and their information and financial statements became more accurate.

Study by Nagano and da Costa Moraes (2013) aimed to determine the importance of artificial intelligence in the accounting field and the role of smart elements in improving accounting output. And by reviewing the previous literature, the study came to the conclusion that reliance on artificial intelligence systems and their introduction in accounting work contributed to reaching more accurate, effective and efficient reports, and the quality of accounting information was higher than that that intelligence-based accounting information systems Artificial intelligence was able to provide useful information on demand, and its outputs were understandable, relevant, reliable and comparable.

In a study by Al-Sayyed et al (2021), the researchers indicated that AI techniques in all their forms have proven their importance in the accounting audit profession, as they contribute to providing auditors with the tools and procedures necessary to complete the audit process in an accurate, smooth and clear manner that serves decision makers. Accordingly, their study aimed to demonstrate the impact of artificial intelligence techniques on the accounting audit process from the point of view of auditors in information technology companies in Jordan. The study adopted the descriptive analytical approach by adopting the questionnaire and distributing it to a sample of (314) auditors. The study came to the conclusion that expert systems have a clear impact on the review and audit process by improving and developing outputs and analyzing evidence in a fast, reliable, comparable and measurable manner.

\section{Artificial intelligence positively influences non-financial performance}

Shrestha et al (2019) aimed to demonstrate the impact of artificial intelligence and its techniques on non-financial organizational performance by looking at the decision-making mechanism. By reviewing the previous literature, the study came to the conclusion that artificial intelligence matrices contribute to facilitating and managing the decision-making process in a way that serves senior and middle management by influencing certain areas of decision-making such as interpretability, speed of decision-making, the possibility of decision repetition and thus reaching a decision based on accurate information capable of completing the required task and solving the problem.

Raisch and Krakowski (2021) aimed in their study to stand on artificial intelligence and the concepts of automation of organizational processes and their impact on administrative processes in the organization, and by focusing on the previous literature, the researchers reached a conclusion that artificial intelligence was flexible enough to enhance administrative processes In all its forms by enhancing interaction with humans, that is, the 
possibility for individuals to deal with the machine side by side in order to reach the complete completion of various tasks leading to superior performance and to enhance many organizational concepts such as empowerment, control, and organizational performance in full.

\section{Model and Objectives}

Based on hypotheses development above, and launching from main aim of study; researcher was able to create a study model that explains the relationship between variable and hence extract hypotheses from model:

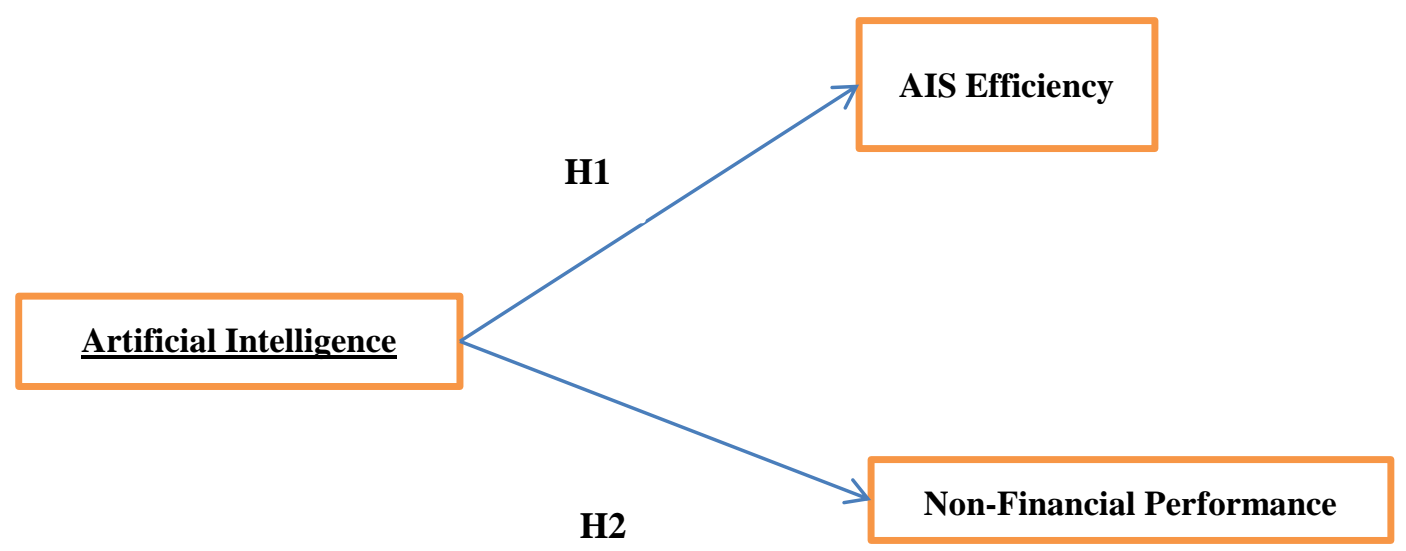

Figure 1. Study Model (Khemakhem et al, 2020)

\section{Hypotheses:}

\section{H1: AI has the ability to enhance efficiency of AIS outcomes}

\section{H2: AI has the ability to enhance non-financial performance}

\section{Methods}

Achieving the goal of the current study came by adopting the quantitative approach, and a questionnaire was built for this purpose - the study tool - and it consisted of two parts. The study population consisted of the total industrial establishments operating in Jordan which reached (9458) operating establishments and registered in the Amman Chamber of Industry until 2021. An appropriate sample was chosen to represent the study community and it consisted of (500) among managers, heads of departments and accountants from senior management and medium.

In line with the precautionary measures of COVID 19 that prevent gatherings and mingling, the questionnaire was uploaded to Google Forms for a period of 8 weeks in order to collect the primary data, and after the period that had elapsed, (409) correctly filled out and complete questionnaire that allowed for statistical analysis was dealt with.

Data analysis was done using SPSS v. On the 23rd, the following statistical tests were used:

- Mean and standard deviation

- Frequency and percentages

- Linear regression

Testing reliability of scale was done depending on Cronbach's Alpha which scored 0.968 and reflected high level of consistency since it was greater than 0.60

\section{Analysis and Discussion}

\section{Demographics}

Responses to questionnaire demographics were calculated as it appeared in table 1 below, it can be seen that majority of respondents were males forming $64.1 \%$ of total sample, who were within age range of (30-34) years old and had a degree of MA in related fields forming $42.5 \%$ of total sample. In addition to that, it appeared 
through the analysis that $60.6 \%$ of the sample was accountants compared to $25.9 \%$ as head departments and $13.4 \%$ as managers of financial units in the organization.

Table 1. Sample Statistics

\begin{tabular}{|c|c|c|c|}
\hline \multicolumn{4}{|c|}{ Age } \\
\hline & & $f$ & $\%$ \\
\hline \multirow[t]{4}{*}{ Valid } & $25-29$ & 125 & 30.6 \\
\hline & $30-34$ & 150 & 36.7 \\
\hline & $35-39$ & 106 & 25.9 \\
\hline & +40 & 28 & 6.8 \\
\hline \multicolumn{4}{|c|}{ Gender } \\
\hline \multirow[t]{2}{*}{ Valid } & Male & 262 & 64.1 \\
\hline & Female & 147 & 35.9 \\
\hline \multicolumn{4}{|c|}{ Education } \\
\hline \multirow[t]{4}{*}{ Valid } & Diploma & 120 & 29.3 \\
\hline & BA & 84 & 20.5 \\
\hline & MA & 174 & 42.5 \\
\hline & $\mathrm{PhD}$ & 31 & 7.6 \\
\hline \multicolumn{4}{|c|}{ Position } \\
\hline \multirow[t]{4}{*}{ Valid } & Manager & 55 & 13.4 \\
\hline & Head Department & 106 & 25.9 \\
\hline & Accountant & 248 & 60.6 \\
\hline & Total & 409 & 100.0 \\
\hline
\end{tabular}

\section{Questionnaire Analysis}

Tables 2, 3 and 4 below showed mean and standard deviation of questionnaire items as according to study variables (AI, NFP and AIS efficiency); as it appeared through analysis, all items of questionnaire scored higher than mean of scale 3.00 which was seen as positive from a statistical point of view. The most positively answered items scored a mean of 4.09/5.00 and was articulated "All AIS output is understandable" compared to the least positively answered item scoring a mean of 3.23/5.00 and articulated "All AIS outputs are objective". The same process took place on study variables in general where mean and standard deviation were calculated. All variables scored higher than mean of scale 3.00 which was statistically positive. The highest mean was for the variable of (AIS Efficiency) compared to the least mean which appeared to be for the variable of (non-financial performance).

Table 2. Mean and standard deviation of Independent Variable (Artificial Intelligence)

\section{Artificial intelligence}

Expert systems are among AI solutions that develops different approaches to solve problems

AI solutions are designed to process events and accounting processes

AI solutions enhances decision making process according to stored data within databases

AI helps to acquire knowledge from the reality of database

$\mathrm{AI}$ is able to support higher management in its decision-taking process

AI helps in planning and supporting different goals

Artificial intelligence allows symbolic knowledge to be represented clearly in graphs, semantics, and text

Symbolic and inferential knowledge is characterized by the ability to extract information from complex data

Artificial intelligence is characterized by the ability to adapt to its cognitive environment

Artificial intelligence allows knowledge to be stored quickly and adequately

Knowledge and inferences are represented according to criteria defined by the organization

Knowledge and inferences are kept securely to preserve them from any manipulation

Artificial intelligence can automatically address problems that may be encountered

The systems within the organization are updated periodically and automatically

The organization's systems are linked to each other at the same time, in an integrated and interactive manner

Artificial intelligence handles accounting errors with logic

AI does not allow data to be manipulated in systems

\begin{tabular}{|c|c}
\hline 3.76 & .995 \\
\hline 3.78 & .922 \\
\hline 3.85 & .859 \\
\hline 3.63 & 1.006 \\
\hline 3.55 & 1.024 \\
\hline 3.26 & 1.106 \\
\hline 3.78 & .907 \\
\hline & \\
\hline 3.35 & 1.086 \\
\hline 4.00 & .867 \\
\hline 3.73 & .975 \\
\hline 3.65 & .979 \\
\hline 3.28 & 1.135 \\
\hline 3.53 & 1.002 \\
\hline 3.60 & .963 \\
\hline 3.79 & 1.027 \\
\hline 3.91 & .971 \\
\hline 4.04 & .919 \\
\hline $\mathbf{3 . 6 7 5 7}$ & $\mathbf{. 6 1 5 3 4}$ \\
\hline
\end{tabular}


Table 3. Mean and standard deviation of $1^{\text {st }}$ dependent Variable (AIS Efficiency)

\begin{tabular}{|c|c|c|}
\hline & Mean & Std. Deviation \\
\hline \multicolumn{3}{|l|}{ AIS Efficiency } \\
\hline AIS output can be compared with standby manual output & 4.08 & .903 \\
\hline AIS outputs depend on each other & 3.87 & .975 \\
\hline Deleting any subsystem from AIS disables the entire system & 3.77 & 1.070 \\
\hline No need to repeat data entry in multiple systems & 3.70 & .954 \\
\hline AIS systems are interconnected to perform specific functions & 3.79 & .943 \\
\hline AIS systems are linked to the goals of the organization & 3.67 & 1.020 \\
\hline AIS interfaces with financial and administrative systems easily & 3.54 & .972 \\
\hline AIS assists senior management in making accounting reviews & 3.49 & 1.017 \\
\hline All AIS outputs are neutral & 3.57 & 1.020 \\
\hline All AIS outputs are objective & 3.23 & 1.105 \\
\hline All AIS outputs are verifiable & 3.42 & 1.040 \\
\hline AIS guarantees the correctness and integrity of data processing & 3.44 & 1.072 \\
\hline AIS provides the organization disclosures for financial reporting items & 3.80 & 1.032 \\
\hline All AIS outputs are reliable and free from bias & 3.92 & .973 \\
\hline All AIS outputs are transparent & 4.06 & 911 \\
\hline All AIS output is understandable & 4.09 & .907 \\
\hline AIS shows the financial position and performance of the organization & 3.89 & .979 \\
\hline Displays AIS output as customized lists & 3.78 & 1.075 \\
\hline AIS provides senior management with annual and interim financial reports & 3.71 & .962 \\
\hline Financial statements can be viewed on the website & 3.81 & .949 \\
\hline It is possible to compare AIS output between several years on the same system & 3.68 & 1.027 \\
\hline AIS Efficiency & 3.7292 & .69359 \\
\hline
\end{tabular}

Table 4. Mean and standard deviation of $2^{\text {nd }}$ dependent Variable (Non-Financial Performance)

Mean Std. Deviation

\begin{tabular}{l|r|r}
\hline \multicolumn{1}{|c|}{ Non-Financial Performance } & \\
\hline $\begin{array}{l}\text { Artificial intelligence enables the organization to manage production based on the number of } \\
\text { units produced }\end{array}$ & 3.56 & .981 \\
\hline $\begin{array}{l}\text { AI enables the organization to access qualitative metrics such as the organization's reputation } \\
\text { and customer satisfaction }\end{array}$ & 3.51 & 1.027 \\
\hline AI meets management's need for improvement & 3.59 & 1.028 \\
\hline AI contributes to clarifying the mechanism of improvement and development & 3.25 & 1.118 \\
\hline AI helps to be an essential tool for digital strategic oversight & 3.44 & 1.046 \\
\hline Through AI, production technology can be developed & 3.46 & 1.084 \\
\hline Information from AI helps prevent errors in the future & 3.78 & 1.063 \\
\hline AI can manage human capital in a seamless way & 3.88 & 1.008 \\
\hline AI can be matched with the goals of the organization & 4.00 & .970 \\
\hline Non-Financial Performance & $\mathbf{3 . 6 0 5 3}$ & $\mathbf{. 7 2 7 5 9}$ \\
\hline
\end{tabular}

\section{Hypotheses Testing}

\section{H1: AI has the ability to enhance efficiency of AIS outcomes}

Table 5. Testing $1^{\text {st }}$ Hypothesis

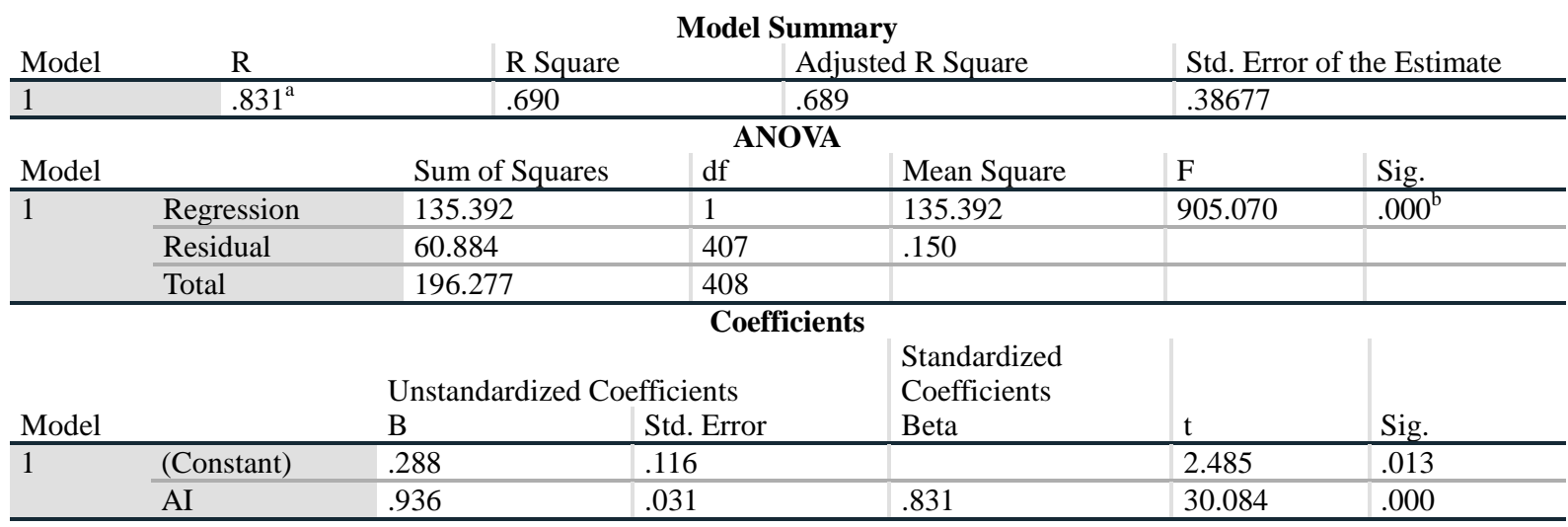


Linear regression was used in this hypothesis and $t$ value $=30.084$ was significant at 0.05 , also $r=0.831$ reflected positive and high relationship between the variables which indicated the fact that AI has the ability to enhance efficiency of AIS outcomes.

\section{H2: AI has the ability to enhance non-financial performance}

Table 6. $2^{\text {nd }}$ Hypothesis

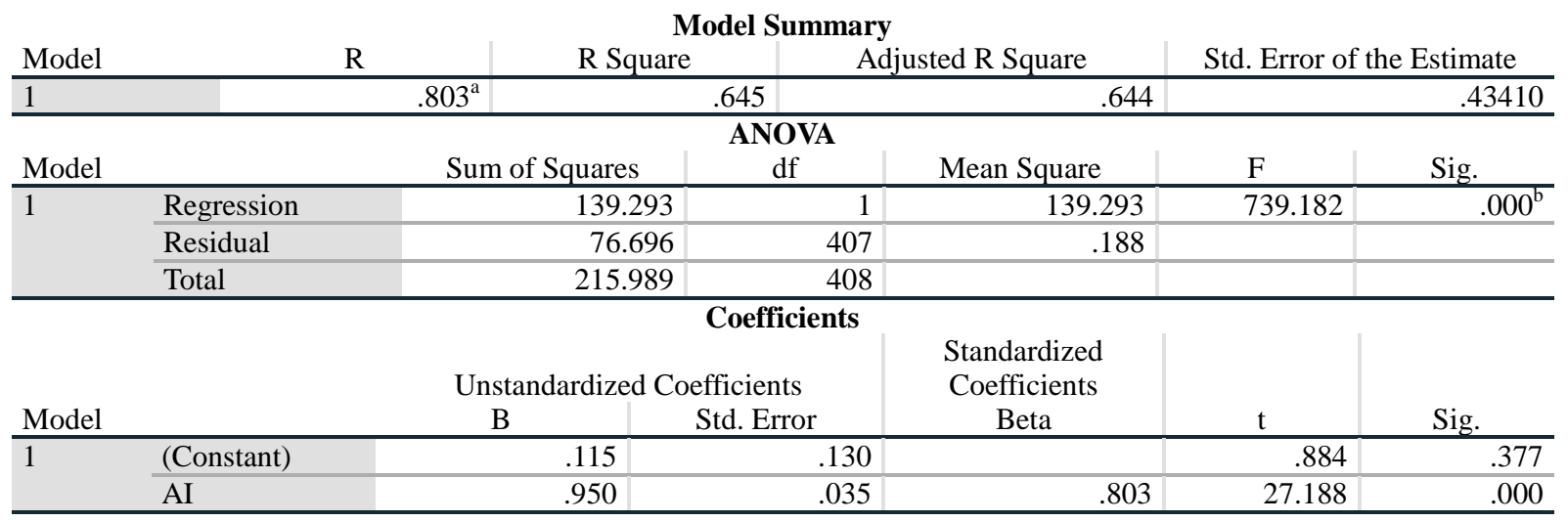

Linear regression was used and $\mathrm{t}$ value $=27.188$ was significant at 0.05 , also $\mathrm{r}=0.803$ reflected positive and high relationship between the variables. So, $\mathrm{AI}$ has the ability to enhance non-financial performance

\section{Discussion of Results}

Aiming to highlight the influence of artificial intelligence on AIS efficiency and non-financial performance, current study adopted the quantitative approach relying on a questionnaire. A sample of (409) managers, head departments and accountants responded to the questionnaire. SPSS was used to screen and process primary data and following findings were reached:

- Their appeared a high level of awareness regarding AI involvement within the profession of accounting given that all respondents had the ability to process the questionnaire and answering it correctly

- Both hypotheses were accepted with a high and positive relationship indicating that AI technique is able to positively influence both AIS efficiency and non-financial performance

\section{Artificial intelligence positively influences efficiency of accounting information systems}

Study was able to reach the needed result indicating that on one side AI techniques are able to monitor and feed AIS applications with what is needed in order to facilitate the process of analyzing the entered data, on the other hand, the managing of this data gave the opportunity to decision makers to handle all problems within organization, strengthening the weak points and exploiting the strength points that are able to deliver the organization to the shore of excellence.

It became clear through the above analysis that the artificial intelligence variable in all its paragraphs had obtained high and high average values, because artificial intelligence contributed significantly to influencing the dependent variables by relying on expert systems, automatic learning and the method of subtracting and presenting information. This result agreed with Askary et al (2018) and Hamadneh et al (2021) who emphasized that artificial intelligence represents the nature of its systems, the brain that controls the organization by relying on expert systems that - based on their design - process accounting events and operations in a fast and accurate manner and provide them on demand in a short time.

It was also found through the study that allowing artificial intelligence to store knowledge in a quick and sufficient manner had a role in maximizing the efficiency of AIS operations through the accounting cloud, which provides decision makers with the opportunity to access information and accounting data from anywhere, provided that the entry permit is secured and the inputs are not manipulated in order to ensure accurate and correct results and information also agreeing with Moraes (2013) and Al-Sayyed et al (2021).

\section{Artificial intelligence positively influences non-financial performance}

With regard to non-financial performance, it has been observed that there is an impact of artificial intelligence techniques on non-financial performance standards, although there are no clear and specific standards for 
non-financial performance, but most researchers agreed that they are standards that may be difficult to measure, such as inventory, efficiency of production processes, customer and employee satisfaction and organizational performance in general. The study proved that artificial intelligence techniques contributed to giving decision makers a comprehensive overview of the organization's non-financial performance by referring to different inputs such as customer base, complaints and suggestions from various customers, the organization's reputation in the market and its market share in addition to its competitive advantage compared to other organizations in same field agreeing with Shrestha et al (2019).

Through the analysis, it has been proven that artificial intelligence techniques provided the organization with the possibility of following up the production lines and their effectiveness based on the existing numbers related to inventory, in addition to the possibility of reaching qualitative standards related to the relationship of the organization in its customers and the extent of their satisfaction.

On the other hand, the study found that artificial intelligence techniques affected the non-financial aspect of organizations by showing weaknesses, improving them, strengths and exploiting them, in addition to showing matrices that contribute to clarifying areas and ways of improvement and development, and thus arriving at studied and clarified strategies related to reaching the goals, this result agreed with Raisch and Krakowski (2021) who emphasized the role of artificial intelligence techniques in managing human capital and organizing the organization's relationship with customers by focusing on the criteria of satisfaction and loyalty.

\section{Conclusion and Recommendations}

Regardless of the influence of AI techniques on performance and efficiency of AIS outcomes, the study confirmed that accounting artificial intelligence contributes significantly to reducing the challenges that accountants may face, and gives preference to work more efficiently and intelligently and in a smooth and easy way, but the human mind cannot be dispensed with in operations fully accounting. Finally, raising the efficiency of artificial intelligence systems enhances the efficiency of the systems used within the organization and thus raises the efficiency of performance. This is proven by the current study by focusing on the use of expert systems that contribute to the acquisition of inferential knowledge from the reality of existing databases, which usually support management capabilities.

Based on what was reached previously, current study recommended:

- $\quad$ Linking the operations of intelligent systems to the goals of the organization as a whole

- Ensure the complete interdependence between the AIS systems and the accounting information in the systems

- Attempting to reach a state of integration and interaction between the systems used within the organization to ensure the unity of information

\section{References}

Acemoglu, D., \& Restrepo, P. (2019). 8. Artificial Intelligence, Automation, and Work (pp. 197-236). University of Chicago Press. https://doi.org/10.7208/chicago/9780226613475.003.0008

Albuhisi, A. M., \& Abdallah, A. B. (2018). The impact of soft TQM on financial performance: The mediating roles of non-financial balanced scorecard perspectives. International Journal of Quality \& Reliability Management. https://doi.org/10.1108/IJQRM-03-2017-0036

Albuhisi, A. M., \& Abdallah, A. B. (2018). The impact of soft TQM on financial performance: The mediating roles of non-financial balanced scorecard perspectives. International Journal of Quality \& Reliability Management. https://doi.org/10.1108/JQRM-03-2017-0036

Al-Hashimy, H. N. H., Al Jubair, A. S., \& Jasim, E. T. (2019). The effect of accounting information systems (AIS) on enterprise resource planning (ERP). Journal of Southwest Jiaotong University, 54(5). https://doi.org/10.35741/issn.0258-2724.54.5.36

Al-Sayyed, S., Al-Aroud, S., \& Zayed, L. (2021). The effect of artificial intelligence technologies on audit evidence. Accounting, 7(2), 281-288. https://doi.org/10.5267/j.ac.2020.12.003

Askary, S., Abu-Ghazaleh, N., \& Tahat, Y. A. (2018, October). Artificial intelligence and reliability of accounting information. In Conference on e-Business, e-Services and e-Society (pp. 315-324). Springer, Cham. https://doi.org/10.1007/978-3-030-02131-3_28

Astuti, E., \& Rahayu, S. M. (2018). The influence of information technology strategy and management support to the internal business process, competitive advantage, financial and non-financial performance of the 
company. International Journal of Web Information Systems. https://doi.org/10.1108/IJWIS-11-2017-0079

Borodin, A., Shash, N., Panaedova, G., Frumina, S., \& Mityushina, I. (2019). The impact of the publication of non-financial statements on the financial performance of companies with the identification of interpectoral features. https://doi.org/10.9770/jesi.2019.7.2(61)

Chukwudi, O. L., Echefu, S. C., Boniface, U. U., \& Victoria, C. N. (2018). Effect of artificial intelligence on the performance of accounting operations among accounting firms in South East Nigeria. Asian Journal of Economics, Business and Accounting, 1-11. https://doi.org/10.9734/AJEBA/2018/41641

Damerji, H., \& Salimi, A. (2021). Mediating effect of use perceptions on technology readiness and adoption of artificial intelligence in accounting. Accounting Education, 30(2), 107-130. https://doi.org/10.1080/09639284.2021.1872035

DeNisi, A. S., \& Murphy, K. R. (2017). Performance appraisal and performance management: 100 years of progress?. Journal of applied psychology, 102(3), 421. https://doi.org/10.1037/ap10000085

Elsharif, T. A. (2019). The elements of accounting information systems and the impact of their use on the relevance of financial information in Wahda Bank-Benghazi, Libya. Open Journal of Business and Management, 7(3), 1429-1450. https://doi.org/10.4236/ojbm.2019.73098

Faccia, A., Al Naqbi, M. Y. K., \& Lootah, S. A. (2019, August). Integrated Cloud Financial Accounting Cycle: How Artificial Intelligence, Blockchain, and XBRL will Change the Accounting, Fiscal and Auditing Practices. In Proceedings of the 2019 3rd International Conference on Cloud and Big Data Computing (pp. 31-37). https://doi.org/10.1145/3358505.3358507

Gunning, D., \& Aha, D. (2019). DARPA's explainable artificial intelligence (XAI) program. AI Magazine, 40(2), 44-58. https://doi.org/10.1609/aimag.v40i2.2850

Haenlein, M., \& Kaplan, A. (2019). A brief history of artificial intelligence: On the past, present, and future of artificial intelligence. California management review, 61(4), 5-14. https://doi.org/10.1177/0008125619864925

Hamadneh, N., Saleh, M., Jawabreh, O., Tahir, M., Al Omari, R., \& Shniekat, N. (2021). The Effect of Artificial Intelligence (AI) on the Quality and Interpretation of Financial Statements in the Hotels Classified in the AQABA Special Economic Zone (ASEZA). https://doi.org/10.20944/preprints202105.0541.v1

Hariyati, H., Tjahjadi, B., \& Soewarno, N. (2019). The mediating effect of intellectual capital, management accounting information systems, internal process performance, and customer performance. International journal of productivity and performance management. https://doi.org/10.1108/IJPPM-02-2018-0049

He, J., Baxter, S. L., Xu, J., Xu, J., Zhou, X., \& Zhang, K. (2019). The practical implementation of artificial intelligence technologies in medicine. Nature medicine, 25(1), 30-36. https://doi.org/10.1038/s41591-018-0307-0

Helmold, M., \& Samara, W. (2019). Progress in Performance Management: Industry Insights and Case Studies on Principles, Application Tools, and Practice. Springer. https://doi.org/10.1007/978-3-030-20534-8

Holzinger, A., Langs, G., Denk, H., Zatloukal, K., \& Müller, H. (2019). Causability and explainability of artificial intelligence in medicine. Wiley Interdisciplinary Reviews: Data Mining and Knowledge Discovery, 9(4), e1312. https://doi.org/10.1002/widm.1312

Ionescu, L. (2019). Big data, blockchain, and artificial intelligence in cloud-based accounting information systems. Analysis and Metaphysics, 18, 44-49. https://doi.org/10.22381/AM1820196

Khemakhem, F., Ellouzi, H., Ltifi, H., \& Ayed, M. B. (2020). Agent-based intelligent decision support systems: a systematic review. IEEE Transactions on Cognitive and Developmental Systems. https://doi.org/10.1109/TCDS.2020.3030571

Kokina, J., \& Davenport, T. H. (2017). The emergence of artificial intelligence: How automation is changing auditing. Journal of emerging technologies in accounting, 14(1), 115-122. https://doi.org/10.2308/jeta-51730

Luo, J., Meng, Q., \& Cai, Y. (2018). Analysis of the Impact of Artificial Intelligence application on the Development of Accounting Industry. Open Journal of Business and Management, 6(4), 850-856. https://doi.org/10.4236/ojbm.2018.64063

Mjongwana, A., \& Kamala, P. N. (2018). Non-financial performance measurement by small and medium sized 
enterprises operating in the hotel industry in the city of Cape Town. African Journal of Hospitality, Tourism and Leisure, 7(1), 1-26.

Nagano, M. S., \& da Costa Moraes, M. B. (2013). Accounting information systems: An intelligent agents approach. African Journal of Business Management, 7(4), 273-284.

Nguyen, T. H. H., Ntim, C. G., \& Malagila, J. K. (2020). Women on corporate boards and corporate financial and non-financial performance: A systematic literature review and future research agenda. International Review of Financial Analysis, 101554. https://doi.org/10.1016/j.irfa.2020.101554

Nyarku, K. M., \& Ayekple, S. (2019). Influence of corporate social responsibility on non-financial performance. Social Responsibility Journal. https://doi.org/10.1108/SRJ-04-2017-0059

Pulakos, E. D., Mueller-Hanson, R., \& Arad, S. (2019). The evolution of performance management: Searching for value. Annual Review of Organizational Psychology and Organizational Behavior, 6, 249-271. https://doi.org/10.1146/annurev-orgpsych-012218-015009

Raisch, S., \& Krakowski, S. (2021). Artificial intelligence and management: The automation-augmentation paradox. Academy of Management Review, 46(1), 192-210. https://doi.org/10.5465/amr.2018.0072

Richards, G., Yeoh, W., Chong, A. Y. L., \& Popovič, A. (2019). Business intelligence effectiveness and corporate performance management: an empirical analysis. Journal of Computer Information Systems, 59(2), 188-196. https://doi.org/10.1080/08874417.2017.1334244

Sari, N. Z. M., Afifah, N. N., Susanto, A., \& Sueb, M. (2019). Quality accounting information systems with 3 important factors in BUMN Bandung Indonesia. Advances in Social Science, Education and Humanities Research, 343(1), 93-96. https://doi.org/10.2991/icas-19.2019.20

Schleicher, D. J., Baumann, H. M., Sullivan, D. W., Levy, P. E., Hargrove, D. C., \& Barros-Rivera, B. A. (2018). Putting the system into performance management systems: A review and agenda for performance management research. Journal of Management, 44(6), 2209-2245. https://doi.org/10.1177/0149206318755303

Shrestha, Y. R., Ben-Menahem, S. M., \& Von Krogh, G. (2019). Organizational decision-making structures in the age of artificial intelligence. California Management Review, 61(4), 66-83. https://doi.org/10.1177/0008125619862257

Tjahjadi, B., \& Soewarno, N. (2019). The mediating effect of intellectual capital, management accounting information systems, internal process performance, and customer performance. International Journal of Productivity and Performance Management, 68(7), 1250-1271. https://doi.org/10.1108/IJPPM-02-2018-0049

Vaishya, R., Javaid, M., Khan, I. H., \& Haleem, A. (2020). Artificial Intelligence (AI) applications for COVID-19 pandemic. Diabetes \& Metabolic Syndrome: Clinical Research \& Reviews, 14(4), 337-339. https://doi.org/10.1016/j.dsx.2020.04.012

Vincent, V. Z., \& Zakkariya, K. A. (2021). Role Of Business Incubation On The Financial And Non-Financial Performance Of Technology Startups: A Multivariate Multiple Regression Analysis. Journal of Entrepreneurship Education, 24(5), 1-16.

\section{Copyrights}

Copyright for this article is retained by the author(s), with first publication rights granted to the journal.

This is an open-access article distributed under the terms and conditions of the Creative Commons Attribution license (http://creativecommons.org/licenses/by/4.0/). 